\title{
Cerebral blood flow as a predictor of outcome following traumatic brain injury
}

\author{
Daniel F. Kelly, M.D., Neil A. Martin, M.D., Rouzbeh Kordestani, M.D., George Counelis, M.D., \\ David A. Hovda, Ph.D., Marvin Bergsneider, M.D., Ehud Shalmon, M.D., Duncan Q. McBride, \\ M.D., Dena Herman, M.S., and Donald P. Becker, M.D.
}

Division of Neurosurgery, Brain Injury Research Center, and Cerebral Blood Flow Laboratory, University of California at Los Angeles School of Medicine, Los Angeles, California; and Department of Epidemiology, University of California at Los Angeles School of Public Health, Los Angeles, California

As part of a prospective study of the cerebrovascular effects of head injury, 54 moderate and severely injured patients underwent 184 133Xe-cerebral blood flow (CBF) studies to determine the relationship between the period of maximum blood flow and outcome. The lowest blood flows were observed on the day of injury (Day 0) and the highest CBFs were documented on postinjury Days 1 to 5. Patients were divided into three groups based on $\mathrm{CBF}$ values obtained during this period of maximum flow: Group 1 (seven patients), CBF less than $33 \mathrm{ml} / 100 \mathrm{~g} /$ minute on all determinations; Group 2 (13 patients), CBF both less than and greater than or equal to $33 \mathrm{ml} / 100 \mathrm{~g} /$ minute; and Group 3 ( 34 patients), CBF greater than or equal to $33 \mathrm{ml} / 100 \mathrm{~g} /$ minute on all measurements. For Groups 1, 2, and 3, mean CBF during Days 1 to 5 postinjury was $25.7 \pm 4,36.5 \pm 4.2$, and $49.4 \pm 9.3 \mathrm{ml} / 100 \mathrm{~g} /$ minute, respectively, and $\mathrm{PaCO}_{2}$ at the time of the CBF study was $31.4 \pm 6,32.7 \pm 2.9$, and $33.4 \pm 4.7 \mathrm{~mm} \mathrm{Hg}$, respectively.

There were significant differences across Groups 1,2, and 3 regarding mean age, percentage of individuals younger than 35 years of age $(42.9 \%, 23.1 \%$, and $76.5 \%$, respectively), incidence of patients requiring evacuation of intradural hematomas $(57.1 \%, 38.5 \%$, and $17.6 \%$, respectively) and incidence of abnormal pupils $(57.1 \%, 61.5 \%$, and 32.4\%, respectively). Favorable neurological outcome at 6 months postinjury in Groups 1, 2, and 3 was $0 \%, 46.2 \%$, and $58.8 \%$, respectively (p < 0.05). Further analysis of patients in Group 3 revealed that of 14 with poor outcomes, six had one or more episodes of hyperemia-associated intracranial hypertension (simultaneous CBF $>55 \mathrm{ml} / 100 \mathrm{~g} /$ minute and ICP $>20$ $\mathrm{mm} \mathrm{Hg}$ ). These six patients were unique in having the highest CBFs for postinjury Days 1 to 5 (mean $59.8 \mathrm{ml} / 100 \mathrm{~g} /$ minute) and the most severe degree of intracranial hypertension and reduced cerebral perfusion pressure $(\mathrm{p}<0.0001)$.

These results indicate that a phasic elevation in CBF acutely after head injury is a necessary condition for achieving functional recovery. It is postulated that for the majority of patients, this rise in blood flow results from an increase in metabolic demands in the setting of intact vasoreactivity. In a minority of individuals, however, the constellation of supranormal CBF, severe intracranial hypertension, and poor outcome indicates a state of grossly impaired vasoreactivity with uncoupling between blood flow and metabolism. 


\section{Key Words * traumatic brain injury * cerebral blood flow * cerebral metabolism * cerebral vasoreactivity * hyperemia * intracranial hypertension}

Over the last two decades, a number of investigations have addressed the significance of dynamic cerebral blood flow (CBF) changes observed in the acute period after severe traumatic brain injury.[5,6,11,22,25,34-37,40,42] These studies have revealed a relatively consistent temporal profile of $\mathrm{CBF}$, essentially characterized by three phases. During the first phase that occurs in the initial hours after injury, blood flows are lowest, falling on average to approximately $50 \%$ of normal.[6,22,36] By as early as 12 hours postinjury the second phase begins, marked by a rise in CBF that approaches or exceeds normal values in some patients and typically persists for the next 4 to 5 days. This phase is followed in turn by a third period of low CBF that lasts for up to 2 weeks postinjury.[5,25,36,37]

Although this triphasic blood flow pattern appears to describe accurately the severely head injured population as a whole, there is considerable heterogeneity among individuals. In some patients, blood flow remains depressed throughout the acute postinjury period, with marked blunting of the second phase, whereas in others a rise in CBF to nearly normal levels occurs early after injury and may remain elevated during both the second and third phases.[37,40,42] The magnitude and temporal profile of these $\mathrm{CBF}$ changes correlate with long-term recovery of function in some instances. For example, blood flows in the first phase postinjury are strongly predictive of outcome.[5,6,22] Not surprisingly, ischemia (CBF $3 / 418 \mathrm{ml} / 100 \mathrm{~g} /$ minute) also correlates with poor outcome, regardless of when documented, although it has been observed most often within 24 hours of injury.[5,22,37]

The significance of subsequent CBF changes in the second and third phases, in which classic ischemia is rarely observed, is less certain. Whereas investigations by Overgaard, et al.,[37] and Robertson, et al.,[40] have shown that higher blood flows during the 1st week to 10 days postinjury are associated with improved outcome, the majority of studies have found no such correlation when measurements were obtained more than 12 hours after insult.[5,22,31] In a report by Jaggi, et al.,[11] CBF correlated with outcome only when patients with hyperemia $(\mathrm{CBF}>33 \mathrm{ml} / 100 \mathrm{~g} /$ minute) were excluded from analysis. The degree of reduction in the cerebral metabolic rate of oxygen $\left(\mathrm{CMRO}_{2}\right)$ was also predictive of recovery. Despite the variability in $\mathrm{CMRO}_{2}$, the study by Jaggi, et al., and those of others have consistently shown a marked reduction in $\mathrm{CMRO}_{2}$ to approximately $50 \%$ of normal for at least 10 days after severe head injury; this has led to the assumption that global metabolic depression is present during this period.[5,11,35,36]

Recent experimental studies, however, indicate that metabolic demands may increase dramatically after head injury, as evidenced by a transient period of hyperglycolysis.[2,10,14,15,17,48] In new work from our institution, a relative or absolute increase in glucose utilization has been observed following severe head injury in humans, as measured by fluorodeoxyglucose positron emission tomography (PET).[3,4] Interestingly, the temporal profile of hyperglycolysis in humans appears to parallel the period of increased CBF typically seen postinjury. These findings raise the question of whether the rise in blood flow seen in many patients is coupled to a rise in metabolic demands, whereas in others, low but not necessarily ischemic CBF may be inadequate, resulting ultimately in cell death and poor outcome.

Given the unclear relationship between acute CBF changes and outcome, this investigation was undertaken specifically to address the period of maximum blood flow postinjury. It was hypothesized that a significant rise from the initial period of hypoperfusion that typically occurs on the day of injury, 
(Day 0), is a necessary condition for achieving favorable outcome. The major goals of this study included: 1) determining if a lack of increase in global CBF on Days 1 to 5 postinjury was associated with poor outcome, despite being significantly above the traditionally defined threshold for ischemia; 2 ) identifying the clinical determinants for patients with consistently low $\mathrm{CBF}$, those with both reduced and normal CBF, and those with consistently normal CBF during this postinjury period; and 3) defining the characteristics of patients with normal CBF but with poor outcome.

\section{CLINICAL MATERIAL AND METHODS}

\section{Patient Enrollment}

From July 1992 to January 1995, 184 acutely head injured patients were prospectively enrolled in the University of California at Los Angeles (UCLA) Brain Injury Research Center Program and treated at either the UCLA Center for Health Sciences or the Harbor-UCLA Medical Center. Informed consent was obtained from family members of all participants in the study. Of the original cohort, 67 patients sustained a moderate or severe head injury, defined as a postresuscitation Glasgow Coma Scale (GCS) score of 13 or less, and underwent serial CBF measurements and intracranial pressure (ICP) monitoring during their stay in the intensive care unit. Within this group, at least one CBF study was performed in each of 54 patients during Days 1 to 5 postinjury, and they are the focus of this report. This cohort differs by 15 patients from that reported in our recent paper concerning hyperemia after head injury.[16] It does not include 10 patients from the previous report because CBF was not recorded on Days 1 to 5 postinjury, and it does include five patients who were excluded from the earlier paper because simultaneous ICP and CBF recordings were not available. Therefore, the two studies include 49 of the same patients.

\section{Determination of CBF}

The CBF was measured by the 133Xe intravenous technique of Obrist, et al.,[35] using a bedside instrument with five external collimators placed over each hemisphere (Ceretronix Cerebrograph Cortexplorer model 10; Laco, Inc., Chesterfield, OH). At the time of CBF measurement, patients' ICP, cerebral perfusion pressure (CPP), and $\mathrm{PaCO}_{2}$ were recorded. Concurrently administered vasoactive drugs (dopamine, phenylephrine, or norepinephrine) and metabolic suppressive agents (high-dose pentobarbital or propofol) were also documented. Blood flow studies performed in the setting of high-dose pentobarbital were included for analysis only if therapy clearly failed, as evidenced by persistently high CBF (> $55 \mathrm{ml} / 100 \mathrm{~g} /$ minute) without a decrease from earlier CBF studies before the patient received metabolic suppressive therapy, and intracranial hypertension persisted (ICP >= $25 \mathrm{~mm}$ $\mathrm{Hg}$ ) without a significant reduction from pretreatment values. Previous investigations assessing the efficacy of high-dose pentobarbital for treatment of intractable intracranial hypertension in head-injured patients have shown a significant and concomitant decrease in both $\mathrm{CBF}$ and ICP in patients who respond favorably to such metabolic suppressive measures.[28,33] Four studies in four patients were included for analysis on this basis, whereas eight studies in four patients were excluded from analysis because therapy was effective or the effects were equivocal. Two CBF studies performed in patients receiving high-dose propofol were also excluded given that relatively little is known about the effects of this agent on CBF in the setting of severe head injury.[43]

As previously described, the CBF15 was determined for each cerebral hemisphere, and global CBF was defined as the average of the two hemispheric rates expressed in milliliters/100 g/minute.[26] Individual 
CBF studies were not adjusted to a normative $\mathrm{PaCO}_{2}$ given the marked variability in both global and regional $\mathrm{PaCO}_{2}$ reactivity after head injury, which makes the use of this adjustment of questionable validity, and because mild hyperventilation was routinely used.[21,31] Instead, mean $\mathrm{PaCO}_{2}$ values at the time of CBF determination were compared between groups.[16] For each patient in whom more than one $\mathrm{CBF}$ measurement was taken for a given $\mathrm{CBF}$ phase, a mean value was determined. Subsequent group analyses used the average of the mean $\mathrm{CBFs}$ for each patient.

\section{Patient Classification}

Patients were divided into three groups based on CBF measurements obtained on Days 1 through 5 postinjury. Group 1 included patients whose CBF was less than $33 \mathrm{ml} / 100 \mathrm{~g} /$ minute on all studies; Group 2 included individuals with CBF both less than and greater than $33 \mathrm{ml} / 100 \mathrm{~g} /$ minute; and Group 3 included patients whose CBF was greater than or equal to $33 \mathrm{ml} / 100 \mathrm{~g} / \mathrm{minute}$ on all determinations. A blood flow of $33 \mathrm{ml} / 100 \mathrm{~g} /$ minute was chosen as the threshold point given that this value is 2 standard deviations (SDs) below normal adult $\mathrm{CBF}\left(44.1 \pm 5.6 \mathrm{ml} / 100 \mathrm{~g} /\right.$ minute) when adjusted for a $\mathrm{PaCO}_{2}$ of 34 $\mathrm{mm} \mathrm{Hg}$, as measured by the 133Xe method.[35] Additionally, this value is at the upper limit of blood flows observed on the day of injury and is significantly above the traditionally defined threshold for infarction of $18 \mathrm{ml} / 100 \mathrm{~g} /$ minute.[5,36] By dividing the cohort into three groups based on this reference $\mathrm{CBF}$, the effect of reduced but nonischemic blood flow during this postinjury period could be addressed.

\section{Transcranial Doppler Studies}

Serial transcranial Doppler studies were performed using a 2-MHz ultrasound probe (Medisonics Neurogard TCD Unit; Neurogard, Inc., Fremont, CA) via the temporal cranial window, as previously described.[26] Vasospasm was defined as a mean middle cerebral artery (MCA) velocity of greater than $120 \mathrm{~cm} / \mathrm{second}$ with an MCA velocity/cervical internal carotid artery velocity ratio of greater than 3 . Patients were classified as having spasm if these criteria were met at least once unilaterally or bilaterally during Days 1 to 5 postinjury.

\section{Recording of ICP and CPP}

The ICP was measured by ventricular catheter in 44 patients or by parenchymal transducer (Camino Corp.; San Diego, CA) in 10 patients. Intracranial hypertension was defined as an ICP greater than 20 $\mathrm{mm} \mathrm{Hg}$ sustained for more than 5 minutes. The ICP and CPP measurements were recorded on an hourly (end-hour) basis, as performed in the Traumatic Coma Data Bank cohort.[24] Cumulative data were obtained for each patient and consisted of average hourly ICP and CPP and the number of hours that ICP was greater than $20 \mathrm{~mm} \mathrm{Hg}$ and CPP less than $70 \mathrm{~mm} \mathrm{Hg}$.

\section{Other Predictors of Outcome}

Additional factors known to be important prognostic indicators after head injury were documented. Systemic hypotension (systolic blood pressure $<90 \mathrm{~mm} \mathrm{Hg}$ ) or an abnormal pupillary response (poorly reactive or an asymmetry of $2 \mathrm{~mm}$ or greater) noted in the prehospital setting or during the first 24 hours of hospitalization were recorded. The first two computerized tomography (CT) scans obtained in each patient were also analyzed for perimesencephalic cistern effacement (compressed or absent), diffuse swelling, diffuse swelling with midline shift of more than $4 \mathrm{~mm}$, diffuse injury with punctate hemorrhages, subarachnoid hemorrhage, evacuated mass lesions, multiple contusions, and gunshot wounds.[7,8,45] An Injury Severity Score was also calculated for each patient.[1] Neurological outcome 
was determined at 6 months postinjury using the Glasgow Outcome Scale (GOS), with favorable outcome defined as good recovery or moderate disability, and poor outcome as severe disability, persistent vegetative state, or death.[12]

\section{Patient Management}

All patients were admitted to the intensive care unit after initial stabilization in the emergency room or after craniotomy for evacuation of intracranial hematoma. Subsequent therapeutic goals included maintenance of ICP at less than $20 \mathrm{~mm} \mathrm{Hg}$ and CPP at greater than $70 \mathrm{~mm} \mathrm{Hg}$. The ICP therapy was implemented in a stepwise fashion and entailed head elevation to $30 \check{\text { s }}$ and mild hyperventilation $\left(\mathrm{PaCO}_{2}\right.$ 30-35 $\mathrm{mm} \mathrm{Hg}$ ) followed by ventricular cerebrospinal fluid drainage, narcotic sedation, neuromuscular blockade, and bolus mannitol therapy as needed. High-dose pentobarbital or propofol were used in select cases for intractable intracranial hypertension refractory to conventional methods. The CPP was maintained at $70 \mathrm{~mm} \mathrm{Hg}$ or above with the use of intravascular volume expansion and vasopressor therapy.

\section{Statistical Analysis}

Between-groups analysis of continuous variables was performed using Student's t-test for comparison of two groups or by analysis of variance (ANOVA) for comparison of more than two groups. Multiple comparisons were not adjusted for an inflated alpha because the level of significance for individual comparisons was so high (typically $\mathrm{p}<0.001$ ). For those comparisons using ANOVA, simple main effects were compared using appropriate post hoc contrasts. Percentage comparisons were performed using a Bernoulli process. The Mann-Whitney U-test was used to assess differences in the median GCS score and the median number of CT diagnoses. All variances were expressed as a SD.

\section{RESULTS}

\section{Patient Characteristics}

The 54 patients ranged in age from 17 to 77 years with a mean age ( \pm SD) of $34.5 \pm 16$ years; $45(83.3 \%)$ were male. Postresuscitation GCS scores ranged from 3 to 13 , with a median of $6 ; 49$ patients $(90.7 \%)$ had an initial GCS score of 8 or less. Closed head injuries occurred in 51 patients $(94.4 \%)$ and gunshot wounds in three $(5.5 \%)$. Eleven patients $(20.4 \%)$ sustained a hypotensive insult and $23(42.6 \%)$ had documentation of an abnormal pupillary response within 24 hours of admission. The median number of CT diagnoses obtained in each patient was three, with a range of zero to eight. Twenty-three patients (42.6\%) underwent craniotomy for evacuation of an epidural (eight), subdural (11), or intracerebral hematoma (five), including one patient who underwent evacuation of a subdural and an intracerebral hematoma. Seven patients (13\%) were treated with high-dose pentobarbital (six patients) or propofol (one patient) for intractable intracranial hypertension. The Injury Severity Score was $31.9 \pm 11$ (mean \pm $\mathrm{SD})$. 


\begin{tabular}{|c|c|c|c|c|c|}
\hline \multicolumn{6}{|c|}{$\begin{array}{l}\text { TABLE } 1 \\
\text { PHASK CHANGES IN CBF AFTER HEAD IN,URV IN } 54 \text { PATIENTS* }\end{array}$} \\
\hline $\begin{array}{l}\text { No. of } \\
\text { Patierts } \\
\text { Tested }\end{array}$ & $\begin{array}{l}\text { Post- } \\
\text { injury } \\
\text { Day }\end{array}$ & $\begin{array}{c}\text { CBF } \\
\text { (mlli } 100 \\
\text { giminj) }\end{array}$ & $\begin{array}{l}\mathrm{PaCO} 2 \\
(\mathrm{~mm} \mathrm{Hg}) \ddagger\end{array}$ & $\begin{array}{l}\mathrm{ICP} \\
{[\mathrm{mmH} H}\end{array}$ & $\begin{array}{l}\mathrm{CPP} \\
\left(\mathrm{mmH} \mathrm{m}^{-}\right.\end{array}$ \\
\hline $\begin{array}{l}14 \\
54 \\
22\end{array}$ & $\begin{array}{c}0 \\
1-5 \\
6-14\end{array}$ & $\begin{array}{l}32.7 \pm 7.1 \\
43.1 \pm 11.5 \\
35.8 \pm 10.0\end{array}$ & $\begin{array}{l}30.5 \pm 3.7 \\
33.0 \pm 4.5 \\
35.6 \pm 5.4\end{array}$ & $\begin{array}{l}16 \pm 6 \\
15 \pm 9 \\
16 \pm 9\end{array}$ & $\begin{array}{l}77 \pm 11 \\
83 \pm 15 \\
81 \pm 14\end{array}$ \\
\hline \multicolumn{6}{|c|}{ 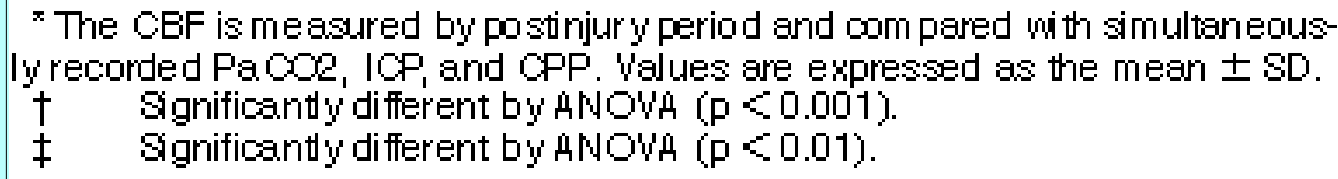 } \\
\hline
\end{tabular}

\section{Temporal Profile of CBF Measurements}

From Days 0 to 14 postinjury, 184 133Xe-CBF studies were performed with a median of three studies per patient (range one-10). Fourteen studies were performed in 14 patients on Day 0, 127 studies were performed in 54 patients from Days 1 to 5, and 43 were performed in 22 patients from Days 6 to 14 . The average CBF on Day 0 was $32.7 \pm 7.1 \mathrm{ml} / 100 \mathrm{~g} / \mathrm{minute}$, during Days 1 to 5 it was $43.1 \pm 11.5 \mathrm{ml} / 100$ $\mathrm{g} /$ minute, and from Days 6 to 14 it was $35.8 \pm 10 \mathrm{ml} / 100 \mathrm{~g} /$ minute $(\mathrm{p}<0.001)$. The mean $\mathrm{PaCO}_{2}$ at the time of CBF determination was $30.5 \pm 3.7 \mathrm{~mm} \mathrm{Hg}$ for Day $0,33 \pm 4.5 \mathrm{~mm} \mathrm{Hg}$ for Day 1 to 5 , and $35.6 \pm$ $5.4 \mathrm{~mm} \mathrm{Hg}$ for Days 6 to 14 ( $\mathrm{p}<0.01$, Table 1). The $\mathrm{PaCO}_{2}$ values were not available for 17 studies $(9.2 \%)$. There were no significant differences in ICP or CPP between the three CBF phases at the time of CBF determination. 


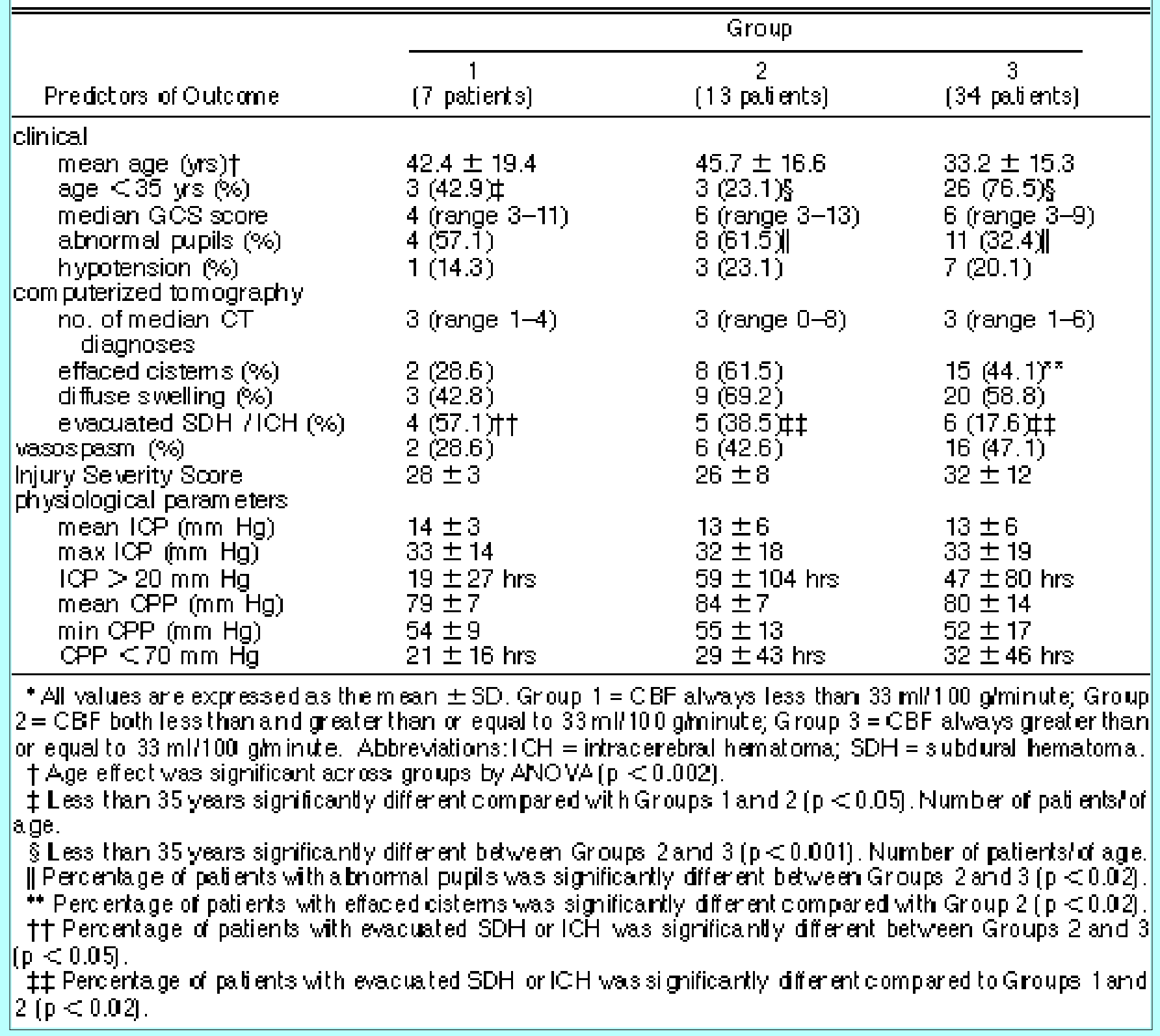

\section{Clinical Determinants of Injury Severity and Outcome by Patient Group}

Predictors of outcome, CT data, and physiological data on ICP and CPP are summarized by group in Table 2. The CBF and outcome results are displayed in Table 3. A brief clinical synopsis is provided for each patient group. 
TABLE 3

OUTCOME IN RELATION TO CBF AS MEASURED ON POSTNURV DAVS 1 TO 5

\begin{tabular}{ccccc}
\hline \hline & \multicolumn{2}{c}{ Flow Values (m ean $\pm \mathrm{SD})$} & & \\
\cline { 2 - 5 } Group & $\begin{array}{c}\text { CBF (mli } \\
100 \text { g'min) }\end{array}$ & $\begin{array}{c}\text { PaCO2 } \\
\text { (mm Hg) }\end{array}$ & $\begin{array}{c}\text { Favorable } \\
\text { Outcome (\%) }\end{array}$ & $\begin{array}{c}\text { Death } \\
\text { (\%) }\end{array}$ \\
\hline 1 (7 patients) & $25.7 \pm 4.0$ & $31.4 \pm 6.0$ & $0(0)^{\times}$ & $4(57.1) \dagger$ \\
2 (13 patients) & $36.5 \pm 4.2$ & $32.7 \pm 2.9$ & $6(46.2)$ & $5(38.5)$ \\
3 (34 patients) & $49.4 \pm 9.3$ & $33.4 \pm 4.7$ & $20(58.8$ 4 & $6(17.6)$ \\
\hline
\end{tabular}

* Significantly different compared to Groups $2(p<0.02)$ and $3(p<0.002)$.

$\dagger$ Significant $y$ different com pared to Group 3 ( $p<0.02$ ).

$\ddagger$ Significantl y different com pared to Group 2 ( $p<0.05$ ).

s Significantl y different com pared to Group $2(p<0.01)$.

Group 1 (CBF $<33 \mathrm{ml} / 100 \mathrm{~g} /$ minute). The mean age of these seven patients was $42.4 \pm 19.4$ years, and the median initial GCS score was 4 , with a range of 3 to 11 . Four patients $(57.1 \%)$ had mass lesions requiring evacuation, including three subdural and one intracerebral hematoma; in two individuals effaced cisterns were seen on CT scanning. The ICP was greater than $20 \mathrm{~mm} \mathrm{Hg}$ for an average of $19 \pm$ 27 hours, and the average CBF was $25.7 \pm 4 \mathrm{ml} / 100 \mathrm{~g} /$ minute during Days 1 to 5 postinjury. There were no favorable outcomes and four patients $(57.1 \%)$ died.

Group $2(\mathrm{CBF}<$ and $>=33 \mathrm{ml} / 100 \mathrm{~g} /$ minute $)$. The mean age of these 13 patients was $45.7 \pm 16.6$ years, and the median GCS score was 6, with a range of 3 to 13. Six patients $(46.2 \%)$ had hematomas that required evacuation (one epidural, four subdural, and one intracerebral), and eight had effaced cisterns detected on CT scanning. The ICP was greater than $20 \mathrm{~mm} \mathrm{Hg}$ for an average of $59 \pm 104$ hours, and the average $\mathrm{CBF}$ was $36.5 \pm 4.2 \mathrm{ml} / 100 \mathrm{~g} /$ minute during Days 1 to 5 postinjury. Favorable outcomes were seen in six patients $(46.2 \%)$ and five $(38.5 \%)$ died.

Group $3(\mathrm{CBF}>=33 \mathrm{ml} / 100 \mathrm{~g} /$ minute). The mean age of these 34 patients was $33.2 \pm 15.3$ years, and the median GCS score was 6 , with a range of 3 to 9 . Thirteen patients $(38.2 \%)$ had hematomas that required evacuation (seven epidural, three subdural, and three intracerebral); 15 had effaced cisterns on CT scanning. The ICP was greater than $20 \mathrm{~mm} \mathrm{Hg}$ for an average of $47 \pm 80$ hours, and the average CBF was $49.4 \pm 9.3 \mathrm{ml} / 100 \mathrm{~g} / \mathrm{minute}$ during Days 1 to 5 postinjury. Twenty patients $(58.8 \%)$ had a favorable outcome and six $(17.6 \%)$ died.

\section{Intergroup Comparisons}

Groups 1, 2, and 3 did not differ significantly in terms of initial GCS score, incidence of hypotension, number of major CT diagnoses, or mean Injury Severity Score. The incidence of MCA vasospasm was also similar across groups; however, four patients (two each in Groups 1 and 2) did have CBF values of less than $33 \mathrm{ml} / 100 \mathrm{~g} /$ minute in association with vasospasm. There were no significant differences between groups in cumulative ICP and CPP values. Significant differences were found, however, in several injury parameters. There was a significant effect of age across groups, with Group 3 being the youngest on average and having the highest percentage of patients younger than 35 years of age. There were significant differences across groups in the incidence of evacuated subdural or intracerebral hematomas, with Group 1 having the highest incidence (57.1\%) and Group 3 the lowest (17.6\%). Additionally, Group 3 had a significantly lower incidence of patients with effaced cisterns and abnormal pupils compared to Group 2. As expected, mean blood flow was also significantly different across groups, with the lowest values documented in Group 1 and the highest seen in Group 3 ( $<<0.001$ ). 
These differences were not related to differences in $\mathrm{PaCO}_{2}$. The rate of favorable outcome at 6 months postinjury was also significantly different between Groups 1, 2, and 3, at 0\%, 42.6\%, and 58.8\%, respectively, whereas the highest and lowest mortality rates occurred in Groups 1 and 3, respectively.

\section{Intragroup Analysis of Patients in Group 3}

In contrast to the 20 patients with good outcomes in Group 3, the 14 individuals with poor outcome had a significantly higher number of CT diagnoses and a higher incidence of pupillary abnormalities and hypotension $(\mathrm{p}<0.05)$. There were no differences between the two subgroups in terms of age, initial GCS score, Injury Severity Score, mean CBF on postinjury Days 1 to 5, or cumulative ICP and CPP data. However, mean ICP ( $p<0.07)$, number of hours that CPP was less than $70 \mathrm{~mm} \mathrm{Hg}(\mathrm{p}<0.06)$, and minimum CPP $(p<0.07)$ showed worsening trends in the poor outcome group. Of the 14 patients with a poor outcome in this group, six had documented hyperemia-associated intracranial hypertension, defined as simultaneous CBF greater than $55 \mathrm{ml} / 100 \mathrm{~g} /$ minute and ICP greater than $20 \mathrm{~mm} \mathrm{Hg}$ on at least one CBF study.[16] Because our previous analyses indicated that these individuals comprise a relatively unique subset of severely injured patients, an intragroup comparison was performed among the 20 patients with good outcomes, the six patients with poor outcomes who had hyperemia-associated intracranial hypertension, and the eight patients with poor outcomes who did not have hyperemia-associated intracranial hypertension (Table 4). 
TABLE 4

CLINICAL PREDICTORS OF OUTCOME IN GROUP 3: GOOD YERSUS POOR OUTCOMES

Outcome

Predctors of Outcome

Good

Poor Wo Hyper-

Poor WiHyper-

(20 pati ents)

tension (8 patients)

tension ( 6 patients)

clinical

mean age (yrs)

age $<35$ years (\%)†

median GCS score

atnormal pupils (\%)

hypotension (\%)

com puterized tomography

median no. of CTdiagnoses

effaced cistems $(\%)^{x \pi}$

diffuse swelling (\%)

evacuated hem atoma (\%)

physiological param eters

mean CBF (ml/100 gim in)

$\mathrm{PaCO}(\mathrm{mm} \mathrm{Hg})$

mean ICP ( $\mathrm{mm} \mathrm{Hg})$

maximum IOP (mm Hg)

hours ICP $>20 \mathrm{~mm} \mathrm{Hg}$

mean CPP ( $\mathrm{mm} \mathrm{Hg}$ )

minimum $\mathrm{OP}(\mathrm{mm} \mathrm{Hg})$

hours CPP $<70 \mathrm{~mm} \mathrm{Hg}$

metabolic suppressi ie therapy

for uncontrollatie ICP (\%)||

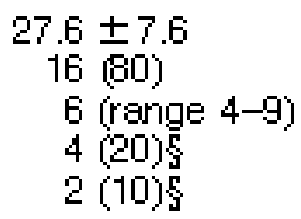

1.5 (range 0-5)川

4 (20)

9 (45)††

$6(30) \neq \ddagger$

$47.1 \pm 7.1$
$34.3 \pm 4.8$
$11 \pm 5$
$30 \pm 19$
$23 \pm 42 \mathrm{hrs}$
$83 \pm 9$
$57 \pm 16$
$18 \pm 23 \mathrm{hrs}$
$1(5)$

$47.1 \pm 7.1$

$34.3 \pm 4.8$

$11 \pm 5$

$30 \pm 19$

$23 \pm 42$ hrs

$83 \pm 9$

$57 \pm 16$

1 (5)

$$
\begin{aligned}
& 37.6 \pm 20.7 \\
& 4(50) \\
& 5 \text { (range } 3-8) \\
& 3 \text { (37.5) } \\
& 2(25)
\end{aligned}
$$
4.5 (range $0-6$ )川
$5(62.5)$
6 (75)
5 (62.5)姉

$46.4 \pm 7.9$

$32.7 \pm 4.7$

$10 \pm 4$

$28 \pm 12$

$6 \pm 11 \mathrm{hrs}$

$82 \pm 9$

$58 \pm 10$

$16 \pm 17 \mathrm{hrs}$

0 (0)
$21.3 \pm 4.6$
6 (100)
4.5 (range $3-6) \neq$
$4(66.7)$ 令
$3(50))^{5}$

3 (range 2-5)

$6(100)$

5 (83.3) )†

2 (33.3)

$59.8 \pm 10.6$

$31.2 \pm 4.3$

$23 \pm 6$

$59 \pm 26$

$156 \pm 98$ hrs

$73 \pm 5$

$28 \pm 15$

$111 \pm 73 \mathrm{hrs}$

5 (83.3)

* Age effect was si gnificant across groups by ANOWA ( $p<0.05)$

† Number of patients younger than 35 years of age was signific antly diferent: poor outcomes with compared to poor outc ome with out hyper enia ass ociated intracrarial hypertensi on and poor outcome without hypertension compared to good outcome ( $p<0.05$ ).

$\ddagger$ The GCS sc ore was significantly different between poor outcome with rypertersion and good outcome $[p<0.02]$.

\$ Percentages of patients with abnormal pupils and hypot ensi on were significantly different in the poor outcome with hypertension com pared to the good outcome subgroup ( $p<0.5$ ).

$\|$ Number of CT dagnoses was significartly different between the poor outcome without hypert ensi on and the good outc one subgroup $[p<0.05]$.

** Percentages of effaced cistems were significantly different: poor outcomes with and without hyperternsion compared to go od outcome $(p<0.0001$ and $p<0.01$, respectively).

t† Percentage with diffuse swe elling was si gnificantly less in the poor outcome with hypertensi on campared to the good outcome subgroup ( $p<0.01)$.

\#‡ Percentage with evac uated hematom a was si grificantly greater in the poor outc one wit hout hyp erternsion com par ed to the good outc one subgroup $[p<0.05]$.

$\$ \$$ Al physiol ogical param eters except $\mathrm{PaCO}_{2}$ and mean CPP were significantly different across groups by ANOWA $(p<0.0001)$.

IIII Percentage with m etabolic suppressive therapy was si gni ficantly different: poor outc om es with compared to without hypertension and poor outcome with hypertension com pared to good outcome $(p<$ $0.0001]$.

Patients with poor outcomes who did not have simultaneous hyperemia and elevated ICP were older on average and had the highest number of CT diagnoses. Six of eight patients had multiple contusions and five had an evacuated intracranial hematoma. However, these patients had minimal intracranial hypertension and reduced CPP. In contrast, the six patients with poor outcomes who had hyperemia-associated intracranial hypertension showed the most severe degree and duration of elevated ICP and reduced CPP and the highest CBF during Days 1 to 5 postinjury ( $<<0.0001)$. Thus, the trend toward significant differences in ICP and CPP between patients in Group 3 with good and poor outcomes was derived almost exclusively from the subset of individuals with hyperemia-associated intracranial 
hypertension. These patients also had the highest incidence of pupillary abnormalities and hypotension, all six had effaced cisterns, and five showed diffuse swelling on CT scanning. Additionally, five of six were treated with metabolic suppressive therapy (four with pentobarbital and one with propofol) for intractable intracranial hypertension, and therapy failed in all of them. If these six patients are excluded from the outcome comparison between Groups 1, 2, and 3, the rate of favorable outcome is $0 \%, 46.2 \%$, and $71.4 \%$, respectively $(\mathrm{p}<0.01)$.

\section{Cerebral Blood Flow as a Continuous Variable}

As a further means of determining the relationship between CBF and outcome, the mean blood flow for each patient during postinjury Days 1 to 5 was compared to the GOS as a continuous variable against other predictors of outcome, including age, GCS score, number of CT diagnoses, and ICP and CPP measurements. A significant effect was seen across the GOS for the factors of age ( $<<0.001)$, hours of ICP greater than $20 \mathrm{~mm} \mathrm{Hg}(\mathrm{p}<0.029)$, and hours of CPP less than $70 \mathrm{~mm} \mathrm{Hg}(\mathrm{p}<0.04)$, whereas the factors of mean ICP ( $p<0.062)$ and CBF ( $<$ < 0.085) approached statistical significance. When the same analysis was conducted on the cohort after exclusion of the six patients with poor outcomes who had hyperemia-associated intracranial hypertension, a significant effect was seen across the GOS for the factors of age ( $p<0.005)$ and CBF $(p<0.013)$ only, whereas the mean ICP $(p<0.12)$, hours of CPP less than $70 \mathrm{~mm} \mathrm{Hg}(\mathrm{p}<0.12)$, and hours of ICP greater than $20 \mathrm{~mm} \mathrm{Hg}(\mathrm{p}<0.13)$ approached statistical significance (Fig. 1).

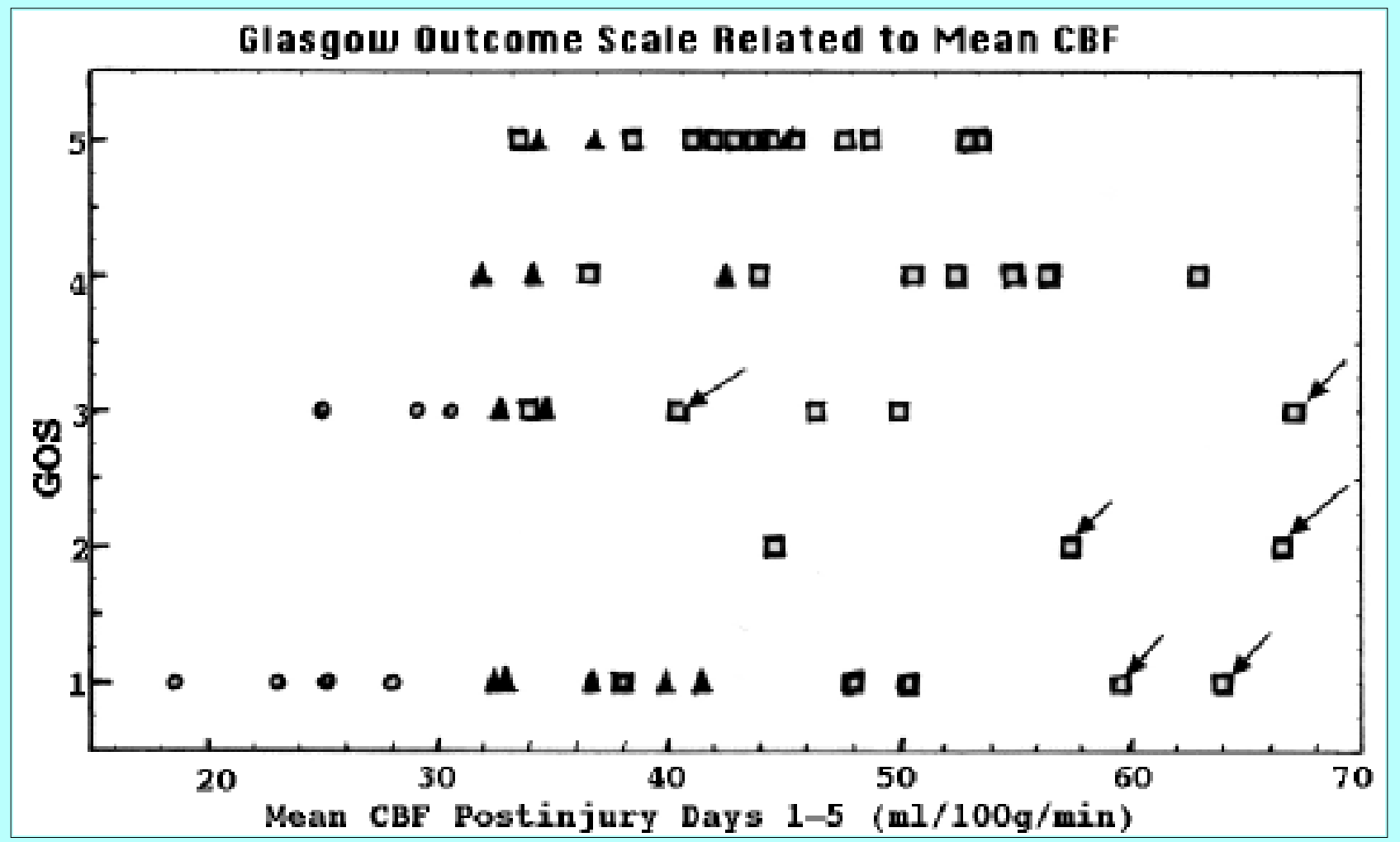

Fig. 1. Graph showing GOS as a function of mean CBF on postinjury Days 1 to 5 . When all 54 patients are included, the effect of $\mathrm{CBF}$ across the GOS approaches statistical significance $(\mathrm{F}=2.18, \mathrm{p}<0.085)$. By excluding the six patients with poor outcome who had hyperemia-associated intracranial hypertension (arrows), the effect of CBF across the GOS becomes highly significant $(\mathrm{F}=4.032, \mathrm{p}<0.013)$. A GOS of $1=$ death, $2=$ vegetative state, $3=$ severe disability, $4=$ moderate disability, $5=$ good recovery. Patients are also identified by group: Group $1=$ circles, Group $2=$ triangles, and Group $3=$ squares. 


\section{DISCUSSION}

\section{Methodological Considerations}

This investigation differs from previous studies addressing the relationship between acute CBF changes and outcome after head injury in that a relatively focused period in which to assess blood flow was chosen, namely the phase of maximum CBF.[5,11,22,31,37,40] Several reports using the 133Xe method have shown that peak flows generally occur within 48 to 72 hours of injury, followed by a decline over the next 2 to 3 days.[25,36,37] In the present study this temporal profile was confirmed, with elevated CBF persisting from Day 1 until Day 5 postinjury; mean CBFs were $41.8 \mathrm{ml} / 100 \mathrm{~g} /$ minute and 44.4 $\mathrm{ml} / 100 \mathrm{~g} / \mathrm{minute}$, respectively. By Day 6, the average CBF had fallen to $33.4 \mathrm{ml} / 100 \mathrm{~g} / \mathrm{minute}$ and remained low through the 2 nd week postinjury.

The subsequent classification of patients into three groups based on CBF measurements of less than or greater than or equal to $33 \mathrm{ml} / 100 \mathrm{~g} /$ minute during this period of maximum flow provided a way to determine how the duration of reduced blood flow might affect outcome. Using this categorization scheme admittedly introduces a potential sampling error, because CBF measurements were not obtained every day in each patient during the study period. In 12 patients, only one measurement was obtained during Days 1 to 5 postinjury and, therefore, these individuals could not be included in Group 2, which was defined by at least two CBF measurements. Additionally, Day 0 CBF studies, which demonstrated the lowest CBFs for the cohort overall, were performed in only 14 patients, and approximately half of these studies were performed 12 to 24 hours postinjury, after the nadir in CBF had likely already occurred.[6,22,36] A final methodological concern is the use of the $133 \mathrm{Xe}$ method, which provides a cortical and subcortical hemispheric blood flow measurement, predominantly of the MCA territory.[34] Consequently, regional areas of critically low blood flow that might have affected long-term outcome may have gone undetected.

\section{Cerebral Blood Flow as a Predictor of Outcome}

Despite these limitations, this report demonstrates that CBF measured on Days 1 through 5 postinjury correlates positively with long-term neurological outcome. Older age and more severe injury (as defined by pupillary abnormalities and incidence of evacuated subdural and intracerebral hematomas) are the most important clinical factors associated with low CBF during this period. These findings indicate that the longer the duration of reduced flow, as determined by the number of observations in which CBF was less than $33 \mathrm{ml} / 100 \mathrm{~g} /$ minute, the worse the outcome will be. The importance of adequate $\mathrm{CBF}$ during this critical period is also supported by ANOVA when mean CBF is treated as a continuous variable, particularly when individuals with hyperemia-associated intracranial hypertension are excluded from analysis. These results raise several important questions: 1) what is the etiology of reduced CBF during the second phase of blood flow; 2) what are the possible mechanisms by which low but nonischemic $\mathrm{CBF}$ results in poor outcome; and 3) why does poor outcome occur in many individuals despite relatively normal blood flow?

\section{Etiology of Hypoperfusion}

Blood flow of less than $33 \mathrm{ml} / 100 \mathrm{~g} /$ minute was observed on at least one occasion during postinjury Days 1 to 5 in 20 (37\%) of 54 patients. The association between advanced age and low CBF in this cohort is not surprising given the decline in blood flow that normally occurs with aging, presumably as a result of reduced cerebral metabolic demands.[27,32] The strong correlation between age and outcome 
seen in this and other studies, although likely to be multifactorial, may be related to a global reduction in cerebral metabolism.[46] Regarding the increased incidence of evacuated subdural or intracerebral hematomas in Groups 1 and 2, a similar correlation between evacuated intradural hematomas and low blood flow has been reported by Bouma, et al.[6] Salvant and Muizelaar[42] also reported that patients with evacuated subdural hematomas had lower CBFs on Days 1 and 2 postinjury compared with those without mass lesions.

Vasospasm is an additional factor that has been associated with reduced CBF after head injury and likely accounts for some instances of low blood flow in this cohort during Days 1 to 5 postinjury.[26] In four patients with vasospasm, CBFs were less than $33 \mathrm{ml} / 100 \mathrm{~g} /$ minute when spasm was documented. However, the incidence of vasospasm was similar among all three groups during this period, and individuals with vasospasm had similar CBFs at the time spasm was detected compared to those without spasm within the same group. Other factors including duration and severity of intracranial hypertension, reduced CPP, and hypocarbia were also similar across groups. Therefore, it is unlikely that these were important contributors to low $\mathrm{CBF}$ in this cohort. It is uncertain whether an excess of vasoconstrictor agents such as neuropeptide $\mathrm{Y}$ or a depletion of nitric oxide are factors in $\mathrm{CBF}$ reductions at the arteriolar level during this period in human head injury.[38,47]

\section{Why Hypoperfusion Correlates With Poor Outcome}

Given that ischemic blood flows were documented in only three of 54 patients during postinjury Days 1 to 5, other factors must be considered in explaining the association of hypoperfusion and poor outcome. Possible causes include: 1) uncoupling between metabolism and blood flow; 2) hypoperfusion-induced depression of protein synthesis; 3 ) global depression of cerebral metabolism resulting from severe primary injury or secondary insults; and 4) global ischemia that is undocumented because of sporadic $\mathrm{CBF}$ measurements.

Metabolic/Blood Flow Uncoupling. An early increase in glycolysis after head injury has been demonstrated in several animal models and recently by means of fluorodeoxyglucose PET following severe human head injury.[2-4,10,14,15,17,18,48] Experimentally, the injury-induced hyperglycolysis occurs during the first few minutes postinjury. In contrast, after severe head injury in humans, regional or global hyperglycolysis appears to have a more prolonged duration, occurring for up to several days postinjury. $[3,4]$ In all six patients from this institution who underwent $133 \mathrm{Xe}-\mathrm{CBF}$ measurement within 24 hours of PET, global blood flows were in the "relative" or "absolute" hyperemia range as defined by Obrist, et al.[35] Although preliminary, these data indicate that in many acutely head injured patients, elevated blood flow may be due to an increase in demand for glucose metabolism, and therefore does not represent classic hyperemia. Additionally, an increase in glycolysis may be in part a compensatory response to a compromised oxidative energy pathway, as evidenced by persistent depression of $\mathrm{CMRO}_{2}$ postinjury.[5,35,36,39,40] Thus, cerebral energy production may become relatively dependent on glycolysis, not only for reestablishing ionic homeostasis but also for other basic cellular functions. Furthermore because glycolysis is a relatively inefficient energy pathway compared to oxidative metabolism, substantial rises in blood flow well above the ischemic threshold may be needed to meet metabolic demands. This imbalance between metabolism and blood flow in which hyperglycolysis occurs in the setting of low but nonischemic CBF may account for the poor outcome seen in many patients. Uncoupling between glycolysis and CBF during the acute period of hyperglycolysis has been documented very early postinjury in several animal models; however, it remains to be observed after head injury in humans.[2,10,18] 
Depression of Protein Synthesis. Cerebral protein synthesis is an additional factor that may be critically dependent on adequate $\mathrm{CBF}$ after head injury and intimately linked to metabolism.[29] Although the duration of cerebral ischemia is known to be a critical determinant of tissue survival and degree of functional recovery, recent data indicate that absolute ischemia is not necessary to induce cell death.[13] In a rat model of MCA occlusion, the CBF threshold for protein synthesis inhibition was significantly higher than that for the loss of adenosine triphosphate.[29] It was concluded that with increasing duration of low CBF, parenchymal survival was determined predominantly by the CBF threshold for inhibition of protein synthesis, rather than the much lower threshold for acute energy failure. This effect of hypoperfusion on cerebral protein synthesis may be highly relevant in head-injured patients in whom persistent global and regional reductions in blood flow commonly occur, yet ischemia, as traditionally defined, is never reached. If subnormal but nonischemic blood flows are of sufficient duration, large-scale cell death may result from this prolonged inhibition of protein synthesis.[9,29,44]

Global Depression of Cerebral Metabolism and Undocumented Ischemia. An additional explanation for the association between persistently low CBF and poor outcome after head injury may be related to global metabolic depression. Marked reduction in both oxidative and glycolytic energy pathways appears most likely to occur in patients sustaining severe primary parenchymal injuries, particularly when associated with hypotension or hypoxia. In this study, hypotension was documented in four of 20 patients with CBF less than $33 \mathrm{ml} / 100 \mathrm{~g} /$ minute, and ischemic blood flows were observed in three patients. Given that ultra-early CBF studies were obtained in only a minority of patients, it is possible that global or regional ischemia went undetected in significantly more patients than was detected. Consequently, ischemia cannot be eliminated as a major contributor to poor outcome in this cohort, particularly because it has been documented in up to one-third of severely head injured patients assessed within 8 hours of injury, and because it correlates so strongly with poor outcome.[5,22,37]

\section{Etiology of Poor Clinical Outcome Despite Relatively Normal CBF}

Although relatively normal CBF on postinjury Days 1 to 5 appears to be necessary for achieving favorable outcome, this factor alone does not ensure functional recovery. Despite CBF being consistently documented at greater than or equal to $33 \mathrm{ml} / 100 \mathrm{~g} /$ minute in Group 3 patients, $41 \%$ of these individuals still had poor outcomes. Subgroup analysis of these patients illustrates the heterogeneous nature of the pathophysiology of the head injury and the fact that there are multiple factors that affect long-term outcome.[30] In the eight patients with poor outcome with no hyperemia-associated intracranial hypertension, older age and a high number of CT-defined abnormalities appear to be the critical factors that precluded functional recovery. Most notably, poor outcome occurred despite the fact that ICP, CPP, and $\mathrm{CBF}$ were maintained at relatively normal levels.

In contrast, the six individuals with at least one episode of hyperemia-associated intracranial hypertension were distinctive in being the youngest, with the lowest GCS scores, the highest CBFs on Days 1 to 5, and the most severe degree of elevated ICP and reduced CPP. In five of six patients metabolic suppressive therapy for intractable intracranial hypertension failed, and three patients sustained a hypotensive episode, indicating that an early ischemic insult had occurred. This injury profile is most consistent with that of severely impaired metabolic vasoreactivity and pressure autoregulation and a state of true hyperemia in which CBF exceeded metabolic demands. A similar clinical profile of patients with severe head injury in whom barbiturate therapy failed has been observed by Nordström and colleagues. [28,33] Experimental work by Lewelt, et al.,[19,20] also indicates that increased injury severity is associated with more profound impairment of vasoreactivity. The study by Jaggi, et al.,[11] 
which showed no correlation between CBF and outcome, may have failed to do so because of a substantial number of patients with true hyperemia. When patients with hyperemia-associated intracranial hypertension were excluded from analysis in the present study, the association between CBF and outcome was even stronger.

\section{CONCLUSIONS}

A phasic elevation in CBF on postinjury Days 1 to 5 appears to be strongly related to a functional recovery after moderate or severe traumatic brain injury. Younger patient age and relatively less severe injury were the most important clinical determinants associated with this favorable blood flow pattern. These findings indicate that the ischemic threshold after head injury is dynamic, rising substantially above the threshold for infarction for the first 5 days postinjury. For the majority of patients, it is postulated that this rise in blood flow results from a relative increase in cerebral metabolic demands in the setting of intact vasoreactivity. However, maintenance of relatively normal blood flow postinjury does not ensure functional recovery. Furthermore, in a minority of patients the presence of markedly elevated $\mathrm{CBF}$, severe intracranial hypertension, and poor outcome suggests a state of uncoupling between blood flow and metabolism resulting from grossly impaired vasoreactivity. Finally, although we acknowledge that a lower CBF threshold of $33 \mathrm{ml} / 100 \mathrm{~g} /$ minute is somewhat arbitrary, this value may have clinical utility in the treatment of head-injured patients, similar to the use of ICP and CPP thresholds of 20 and $70 \mathrm{~mm} \mathrm{Hg}$, respectively.[23,41]

\section{References}

1. The Abbreviated Injury Scale, 1990 Revision. Des Plaines, Ill: Association for the Advancement of Automotive Medicine, 1990

2. Andersen BJ, Marmarou A: Post-traumatic selective stimulation of glycolysis. Brain Res 585:184-189, 1992

3. Bergsneider M, Hovda DA, Shalmon E, et al: Cerebral hyperglycolysis following severe human traumatic brain injury in humans: a positron emission tomography study. J Neurosurg 86:241-251, 1997

4. Bergsneider M, Kelly DF, Shalmon E, et al: Dynamic changes in cerebral glucose metabolism following severe head injury as measured by positron emission tomography. J Cereb Blood Flow Metab 15 (Suppl 1):S26, 1995 (Abstract)

5. Bouma GJ, Muizelaar JP, Choi SC, et al: Cerebral circulation and metabolism after severe traumatic brain injury: the elusive role of ischemia. J Neurosurg 75:685-693, 1991

6. Bouma GJ, Muizelaar JP, Stringer WA, et al: Ultra-early evaluation of regional cerebral blood flow in severely head-injured patients using xenon-enhanced computerized tomography. J Neurosurg 77:360-368, 1992

7. Eisenberg HM, Gary HE Jr, Aldrich EF, et al: Initial CT findings in 753 patients with severe head injury. A report from the NIH Traumatic Coma Data Bank. J Neurosurg 73:688-698, 1990

8. Gennarelli TA, Spielman GM, Langfitt TW, et al: Influence of the type of intracranial lesion on outcome from severe head injury. A multicenter study using a new classification system. J Neurosurg 56:26-32, 1982 
9. Hovda DA, Becker DP, Katayama Y: Secondary injury and acidosis. J Neurotrauma 9 (Suppl 1):S47-S60, 1992

10. Hovda DA, Lee SM, Smith ML, et al: The neurochemical and metabolic cascade following brain injury: moving from animal models to man. J Neurotrauma 12:903-906, 1995

11. Jaggi JL, Obrist WD, Gennarelli TA, et al: Relationship of early cerebral blood flow and metabolism to outcome in acute head injury. J Neurosurg 72:176-182, 1990

12. Jennett B, Bond M: Assessment of outcome after severe brain damage. A practical scale. Lancet 1:480-484, 1975

13. Jones TH, Morawetz RB, Crowell RM, et al: Thresholds of focal cerebral ischemia in awake monkeys. J Neurosurg 54:773-782, 1981

14. Kawamata T, Katayama Y, Hovda DA, et al: Administration of excitatory amino acid antagonists via microdialysis attenuates the increase in glucose utilization seen following concussive brain injury. $\mathbf{J}$ Cereb Blood Flow Metab 12:12-24, 1992

15. Kawamata T, Katayama Y, Hovda DA, et al: Lactate accumulation following concussive brain injury: the role of ionic fluxes induced by excitatory amino acids. Brain Res 674:196-204, 1995

16. Kelly DF, Kordestani RK, Martin NA, et al: Hyperemia following traumatic brain injury: relationship to intracranial hypertension and outcome. J Neurosurg 85:762-771, 1996

17. Kuroda Y, Inglis FM, Miller JD, et al: Transient glucose hypermetabolism after acute subdural hematoma in the rat. J Neurosurg 76:471-477, 1992

18. Lee SM, Lifshitz J, Hovda DA, et al: Focal cortical impact injury produces immediate and persistent deficits in metabolic autoregulation. J Cereb Blood Flow Metab 15 (Suppl 1):S722, 1995 (Abstract)

19. Lewelt W, Jenkins LW, Miller JD: Autoregulation of cerebral blood flow after experimental fluid percussion injury of the brain. J Neurosurg 53:500-511, 1980

20. Lewelt W, Jenkins LW, Miller JD: Effects of experimental fluid-percussion injury of the brain on cerebrovascular reactivity to hypoxia and to hypercapnia. J Neurosurg 56:332-338, 1982

21. Marion DW, Bouma GJ: The use of stable xenon-enhanced computed tomographic studies of cerebral blood flow to define changes in cerebral carbon dioxide vasoresponsivity caused by a severe head injury. Neurosurgery 29:869-873, 1991

22. Marion DW, Darby J, Yonas H: Acute regional cerebral blood flow changes caused by severe head injuries. J Neurosurg 74:407-414, 1991

23. Marmarou A, Ward JD, Young HF, et al: Impact of ICP instability and hypotension on outcome in patients with severe head trauma. J Neurosurg 75 (Suppl):S59-S66, 1991

24. Marmarou A, Ward JD, Young HF, et al: NINDS Traumatic Coma Data Bank: intracranial pressure monitoring methodology. J Neurosurg 75 (Suppl):S21-S27, 1991

25. Martin NA, Benalcazar HE, Alexander M, et al: Characterization of cerebral hemodynamic phases 
that follow severe head trauma (hypoperfusion, hyperemia, vasospasm, resolution). J Neurotrauma 12:432, 1995 (Abstract)

26. Martin NA, Doberstein C, Zane C, et al: Posttraumatic cerebral arterial spasm: transcranial Doppler ultrasound, cerebral blood flow, and angiographic findings. J Neurosurg 77:575-583, 1992

27. Melamed E, Lavy S, Bentin S, et al: Reduction in regional cerebral blood flow during normal aging in man. Stroke 11:31-35, 1980

28. Messeter K, Nordström CH, Sundbärg G, et al: Cerebral hemodynamics in patients with acute severe head trauma. J Neurosurg 64:231-237, 1986

29. Mies G, Ishimaru Y, Xie Y, et al: Ischemic thresholds of cerebral protein synthesis and energy state following middle cerebral artery occlusion in rat. J Cereb Blood Flow Metab 11:753-761, 1991

30. Miller JD, Piper IR, Dearden NM: Management of intracranial hypertension in head injury: matching treatment with cause. Acta Neurochir Suppl 57:152-159, 1993

31. Muizelaar JP, Marmarou A, DeSalles AAF, et al: Cerebral blood flow and metabolism in severely head-injured children. Part 1: Relationship with GCS score, outcome, ICP, and PVI. J Neurosurg 71:63-71, 1989

32. Naritomi H, Meyer JS, Sakai F, et al: Effects of advancing age on regional cerebral blood flow; studies in normal subjects and subjects with risk factors for atherothrombotic stroke. Arch Neurol 36:410-416, 1979

33. Nordström CH, Messeter K, Sundbärg G, et al: Cerebral blood flow, vasoreactivity, and oxygen consumption during barbiturate therapy in severe traumatic brain lesions. J Neurosurg 68:424-431, 1988

34. Obrist WD, Gennarelli TA, Segawa H, et al: Relation of cerebral blood flow to neurological status and outcome in head-injured patients. J Neurosurg 51:292-300, 1979

35. Obrist WD, Langfitt TW, Jaggi JL, et al: Cerebral blood flow and metabolism in comatose patients with acute head injury. Relationship to intracranial hypertension. J Neurosurg 61:241-253, 1984

36. Obrist WD, Marion DW, Aggarwal S, et al: Time course of cerebral blood flow and metabolism in comatose patients with acute head injury. J Cereb Blood Flow Metab 13 (Suppl 1):S571, 1993 (Abstract)

37. Overgaard J, Mosdal C, Tweed WA: Cerebral circulation after head injury. Part 3: Does reduced regional cerebral blood flow determine recovery of brain function after blunt head injury? J Neurosurg 55:63-74, 1981

38. Paulson OB, Strandgaard S, Edvinsson L: Cerebral autoregulation. Cerebrovasc Brain Metab Rev 2:161-192, 1990

39. Ritter AM, Robertson CS: Cerebral metabolism. Neurosurg Clin North Am 5:633-645, 1994

40. Robertson CS, Contant CF, Gokaslan ZL, et al: Cerebral blood flow, arteriovenous oxygen difference, and outcome in head injured patients. J Neurol Neurosurg Psychiatry 55:594-603, 1992

41. Rosner MJ, Rosner SD, Johnson AH: Cerebral perfusion pressure: management protocol and clinical 
results. J Neurosurg 83:949-962, 1995

42. Salvant JB Jr, Muizelaar JP: Changes in cerebral blood flow and metabolism related to the presence of subdural hematoma. Neurosurgery 33:387-393, 1993

43. Stewart L, Bullock R, Rafferty C, et al: Propofol sedation in severe head injury fails to control high ICP, but reduces brain metabolism. Acta Neurochir Suppl 60:544-546, 1994

44. Thilmann R, Xie Y, Kleihues P, et al: Persistent inhibition of protein synthesis precedes delayed neuronal death in postischemic gerbil hippocampus. Acta Neuropathol 71:88-92, 1986

45. Toutant SM, Klauber MR, Marshall LF, et al: Absent or compressed basal cisterns on first CT scan: ominous predictors of outcome in severe head injury. J Neurosurg 61:691-694, 1984

46. Vollmer DG, Torner JC, Jane JA, et al: Age and outcome following traumatic coma: why do older patients fare worse? J Neurosurg 75 (Suppl):S37-S49, 1991

47. Wang Q, Paulson OB, Lassen NA: Effect of nitric oxide blockage by NG-nitro-L-arginine on cerebral blood flow response to changes in carbon dioxide tension. J Cereb Blood Flow Metab 12:947-953, 1992

48. Yoshino A, Hovda DA, Kawamata T, et al: Dynamic changes in local cerebral glucose utilization following cerebral concussion in rats: evidence of a hyper- and subsequent hypometabolic state. Brain Res 561:106-119, 1991

Manuscript received May 8, 1996.

Accepted in final form November 15, 1996.

This work was supported in part by Grant No. NS 30308 from the National Institute for Neurological Disorders and Stroke and by the Lind Lawrence Foundation.

Address reprint requests to: Daniel F. Kelly, M.D., Division of Neurosurgery, Room 18-218A NPI, University of California at Los Angeles, Box 957039, Los Angeles, California 90095-7039. 